\title{
Medical education needs digital boost
}

$\mathrm{W}$ e live in a digital world, and medical educators need to not only acknowledge that but also get onboard, says technology expert Dr. Alireza Jalali. Embracing social media and other technologies only provides more tools to educate medical students and patients, says Jalali, who presented these and other ideas at the International Resident Leadership Summit, held in Toronto Oct. 25 and 26.

"You can go to the rooftops and shout about how Dr. Google is bad, but it doesn't matter. People are still going to Google stuff. What we have to do is create websites that will show up on Google," says Jalali, head of anatomy and teaching chair at the University of Ottawa's faculty of medicine. "The bottom line is that learners are using these tools, and if you don't, you will fall behind."

Medical educators have an obligation to improve health care, says Jalali, yet many doctors and other medical professionals are sometimes discouraged from joining platforms such as Facebook and Twitter, where people go to learn about medical topics. One reason the antivaccine movement has grown so strong, he says, is that its members are so active in the digital world. Physicians will do little to dispel such medical misinformation if they fail to go where patients gather.

"You can tweet about these things. You can post on Facebook pages. That's the way you do health advocacy these days," says Jalali, who is also a social media in medical education advisor at the Royal College of Physicians and

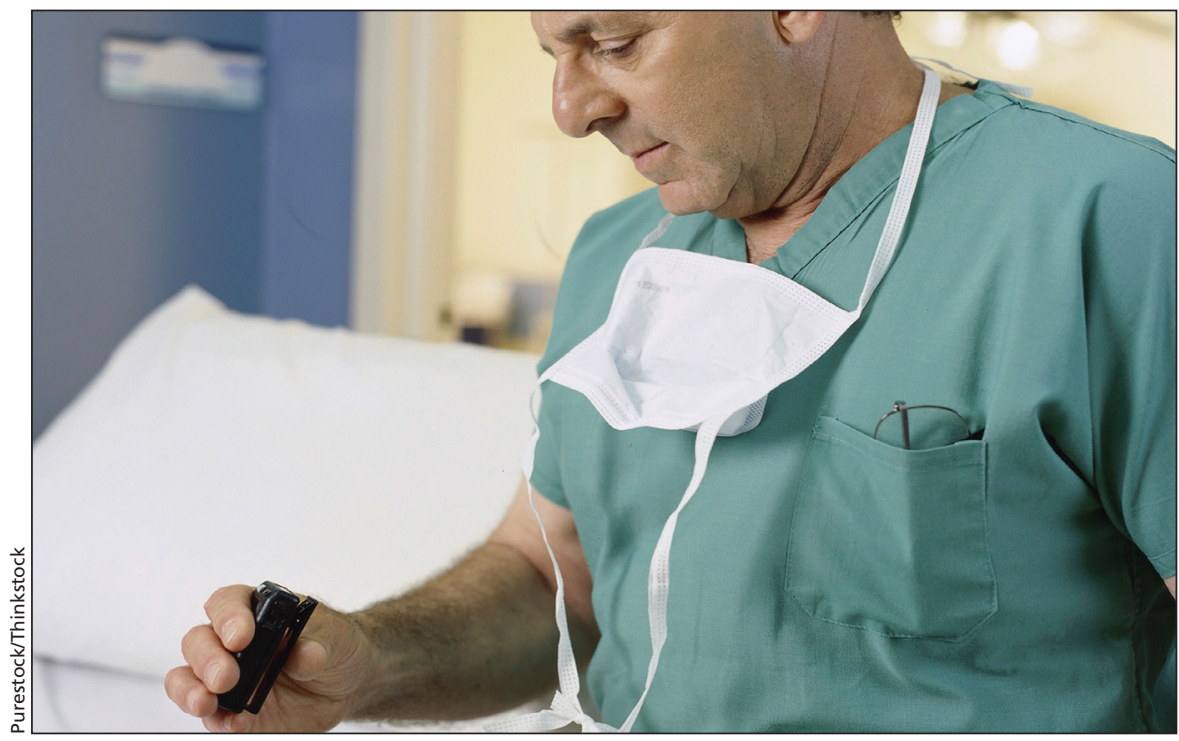

The fact that pagers still appear in health care, and hardly anywhere else, is a sign medicine has been slow to join the digital world.

Surgeons. "There are a billion people on Facebook. We cannot just ignore them."

Medical students can also benefit from social media and other technologies, he says. In some hospitals, for example, medical residents discuss topics from grand rounds on Twitter. Residents can also learn to use hashtags on Twitter to curate information relevant to their field of study. Medical students can use Google+ Hangout to study and review notes together when in different locations.

It is also becoming increasingly important for young doctors to get a head start on gaining control of their online reputations, says Jalali. "It's about creating digital footprints for themselves. You need to have a digital footprint, so when people Google you, you are proud of what comes up."
Too often, medical schools and hospitals make students revert to using older and less efficient technologies, says Jalali. For example, many young students prefer communicating electronically via text rather than email. Yet, even though texting is more efficient and receives far less spam, they are sometimes not given the option of receiving information this way.

"Instead of using their knowledge about technology in the health care system, we impose on them technologies that we used 10 years ago," says Jalali. "We need champions and leaders. Medical students have enough challenges to worry about. They don't need to fight a system that is forcing them to use email." — Roger Collier, CMAJ

CMAJ 2014. DOI:10.1503/cmaj.109-4932 